\title{
Evaluation of fluorimetry and direct visualization to interpret results of a loop- mediated isothermal amplification kit to detect Leishmania DNA
}

\author{
Ana V. Ibarra-Meneses ${ }^{1}$, Israel Cruz², Carmen Chicharro ${ }^{1}$, Carmen Sánchez ${ }^{1}$, Sylvain Biéler², Tobias Broger², \\ Javier Moreno ${ }^{1}$ and Eugenia Carrillo ${ }^{1 *}$
}

\begin{abstract}
Background: Nucleic acid amplification tests (NAATs) have proven to be advantageous in the diagnosis of leishmaniases, allowing sensitive diagnosis of: (i) cutaneous leishmaniasis in long duration lesions and (ii) visceral leishmaniasis using a less-invasive sample like peripheral blood, in opposition to tissue aspiration required for parasite demonstration by microscopy. Despite their benefits, the implementation of NAATs for leishmaniasis diagnosis at the point-of-care has not been achieved yet, mostly due to the complexity and logistical issues associated with PCR-based methods.
\end{abstract}

Methods: In this work, we have evaluated the performance of a ready-to-use loop-mediated isothermal amplification (LAMP) kit using two real time fluorimeters to amplify leishmanial DNA obtained by silica columnbased and Boil \& Spin protocols.

Results: The different approaches used to run and interpret the LAMP reactions showed a performance equivalent to PCR and real-time PCR, using spiked and clinical samples. The time to positivity obtained with real-time fluorimetry showed an excellent correlation with both $C t$ values and parasite load from real-time quantitative PCR.

Conclusions: The results obtained open the possibility of using a highly stable, ready-to-use LAMP kit for the accurate diagnosis of leishmaniasis at the point-of-care. Furthermore, the feasibility of relating time to positivity, determined with a portable real-time fluorimeter, with the parasite burden could have a wider application in the management of leishmaniasis, such as in treatment efficacy monitoring or as a pharmacodynamics tool in clinical trials.

Keywords: Leishmaniasis, Visceral leishmaniasis, Diagnostics, Loop-mediated isothermal amplification, LAMP, Lessinvasive diagnosis, Non-invasive diagnosis, Loopamp ${ }^{\text {TM }}$ Leishmania detection kit, Real-time fluorimeters, Boil \& Spin

\section{Background}

The loop-mediated isothermal amplification (LAMP) method enables the robust, fast, simple and highly specific amplification of nucleic acids. Since it was developed, LAMP has been used in several molecular diagnostic applications $[1,2]$. In the field of infectious diseases it has made possible the diagnosis at the point-of-care (POC) level. For example, LAMP kits have been successfully

\footnotetext{
* Correspondence: ecarrillo@isciii.es

${ }^{1}$ WHO Collaborating Centre for Leishmaniasis, National Centre for

Microbiology, Instituto de Salud Carlos III, Madrid, Spain

Full list of author information is available at the end of the article
}

developed for malaria and tuberculosis by the Eiken Chemical Co. (Japan), and the latter was recently endorsed by the World Health Organization [3-5]. The development of simple and easy-to-implement nucleic acid amplification tests (NAATs) such as LAMP has gained attention as these methods could enable accurate diagnosis at the POC in developing countries where access to laboratories is limited [6].

A LAMP kit for the diagnosis of leishmaniasis at the POC, the Loopamp ${ }^{\text {ma }}$ Leishmania Detection Kit, has been recently developed by the Eiken Chemical Co., FIND and partners. This LAMP test uses primers targeting the

(c) The Author(s). 2018 Open Access This article is distributed under the terms of the Creative Commons Attribution 4.0 International License (http://creativecommons.org/licenses/by/4.0/), which permits unrestricted use, distribution, and reproduction in any medium, provided you give appropriate credit to the original author(s) and the source, provide a link to the Creative Commons license, and indicate if changes were made. The Creative Commons Public Domain Dedication waiver (http://creativecommons.org/publicdomain/zero/1.0/) applies to the data made available in this article, unless otherwise stated. 
$18 S$ rRNA gene and the kDNA minicircles, and is specific for the genus Leishmania. The kit is in a readyto-use format and is composed of dried-down reagents, including primers, Bacillus stearothermophilus (Bst) DNA polymerase and calcein, so that no cold chain for transport and storage is required, and reactions can be set up at ambient temperature. The kit allows for different approaches to detect the amplified products. Before amplification, calcein contained in the dried reagents in each of the reaction tubes is in a quenched state, bound to manganese ions. Once the LAMP reaction starts, the pyrophosphate ions that are generated bind to the manganese ions, releasing calcein, thus generating fluorescent light that is detectable by the naked eye. This signal can be enhanced by illumination with UV or blue light. Real-time monitoring of the fluorescence associated to the amplification is possible using a fluorimeter, and it is also possible to assess the amplification using a real-time turbidimeter to measure the turbidity caused by the precipitation of magnesium pyrophosphate, a by-product of the reaction.

LAMP can amplify target DNA in different biological matrices and even in the presence of fresh blood components that usually inhibit PCR reactions, such as haemoglobin, IgG or IgM [7, 8]. However, there can be situations where the visual assessment of the amplified products can be challenging, like in crude DNA lysate preparations from blood [9, 10]. In addition, direct examination of changes in fluorescence intensity with the naked eye, even under UV or blue light, is dependent on, often subjective, human interpretation. To overcome these problems a number of approaches have been developed during the last decade to improve the detection of the amplified products either by end-point or realtime assessment, including electrochemical, optical and $\mathrm{pH}$-sensing-based detection systems $[8,11]$. Various incubators that can be used to run LAMP reactions are commercially available. Some of them, such as the LF160 (Eiken Chemical Co., Japan), are designed for visual assessment of test results by naked eye using a blue light. Others, such as the LA-320C (Eiken Chemical Co.) can perform real-time turbidity measures. Both the LF160 and the LA-320C are designed to accommodate LAMP reaction tubes made by Eiken Chemical, whose shape is slightly different from standard PCR tubes. By contrast, incubators made by other manufacturers are usually not designed for Eiken Chemical tubes. For example, the Genie III $^{\circledR}$ (OptiGene Limited, Horsham, UK) is a compact, portable, battery-operated incubator including real-time fluorimetry, which is designed to accommodate standard PCR tubes. In 2014, FIND facilitated a modification of the design of the Genie III ${ }^{\circ}$ by OptiGene so that it could be used with LAMP tubes made by Eiken Chemical. FIND also supported a study at the Institute of Primate Research (Kenya) to compare the LF-160, the LA-320C and the Genie III ${ }^{\circ}$ using the Loopamp $^{\mathrm{Tm}}$ Trypanosoma brucei Detection Kit produced by Eiken Chemical (manuscript in preparation). To contribute to this subject we evaluated the performance of

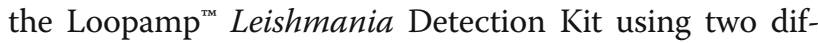
ferent real-time fluorimeters and an incubator with coupled blue LED light illumination.

\section{Methods \\ Study site}

The study was conducted at the WHO Collaborating Centre for Leishmaniasis, National Centre for Microbiology, Instituto de Salud Carlos III, Madrid, Spain (WHOCCL-ISCIII), which is also the national reference laboratory for leishmaniasis.

\section{Biological materials}

The following biological materials were used to create the panels tested in the three experiments described below: (i) Leishmania infantum promastigotes (strain MHOM/ES/ 2014/LLM-2240) cultured in Novy-MacNeal-Nicolle medium medium; (ii) heparin-treated peripheral blood and bone marrow samples from confirmed and nonconfirmed visceral leishmaniasis (VL) suspects stored at $-20{ }^{\circ} \mathrm{C}$ at the WHOCCL-ISCIII collection on leishmaniasis, registered at the National Biobank Register, Section Collections, Spain with the collection Reference ID: C. 0000898; and (iii) freshly collected heparin-treated peripheral blood from a healthy volunteer.

\section{DNA extraction procedures}

DNA was purified from pellets of cultured L. infantum promatigotes and from $95 \mu \mathrm{l}$ of heparin-treated peripheral blood and bone marrow aspirates using the QIAamp DNA Mini Kit (Qiagen, Hilden, Germany). The DNA was eluted in $100 \mu \mathrm{l}$ PCR grade water and processed immediately or stored at $-20{ }^{\circ} \mathrm{C}$ until analysis. When DNA was extracted from $L$. infantum promastigotes its concentration was estimated using a NanoDrop ${ }^{\mathrm{TM}}$ spectrophotometer (Thermo Scientific, Wilmington, USA) and adjusted according to the experiments described below. Measures were taken in duplicates. Additionally, DNA was also purified from biological samples using a "Boil \& Spin" protocol, as follows: $95 \mu$ l heparin-treated whole blood or bone marrow aspirate was mixed with $5 \mu \mathrm{l} 10 \%$ SDS by inversion 10 times in a $1.5 \mathrm{ml}$ microcentrifuge tube with screw cap, allowed to stand for $10 \mathrm{~min}$ at room temperature and mixed again. After adding $400 \mu \mathrm{l}$ PCR grade water the mix was incubated in a heating block at $90{ }^{\circ} \mathrm{C}$ for $10 \mathrm{~min}$. The mix was then spun for 3 min at maximum speed in a bench top microcentrifuge $(13,000 \times r p m)$ and the supernatant containing the DNA 
was recovered and processed immediately or stored at $-20{ }^{\circ} \mathrm{C}$ until analysis.

\section{Nucleic acid amplification tests LAMP}

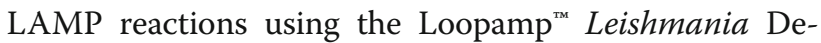
tection Kit (Eiken Chemical Co.) were performed using $3 \mu \mathrm{l}$ purified DNA and run in two different fluorimeters and one incubator, as described below.

\section{Nested PCR and real-time quantitative $P C R$}

DNA samples were also tested by Leishmania nestedPCR (LnPCR) and real-time quantitative PCR (qPCR), both targeting the $18 S$ rRNA (SSU rRNA) gene. Biological samples from the WHOCCL-ISCIII collection had been previously tested by LnPCR, with VL confirmed cases being positive, and non-confirmed VL suspects and healthy controls being negative. This test was repeated in this study to confirm sample integrity. LnPCR was performed with $3 \mu \mathrm{l}$ DNA following the procedure described elsewhere [12]. qPCR was also performed with $3 \mu \mathrm{l}$ DNA using a LightCycler 2.0 high speed thermal cycler and the LightCycler FastStart DNA Master SYBR Green I kit (Roche Diagnostics, Mannhein, Germany) following the protocol described elsewhere. Quantification was accomplished by means of a standard curve which consisted of serial dilutions of L. infantum DNA (strain JPC, MCAN/ES/98/LLM-722) ranging from the equivalent of $10^{4}$ to $10^{-7}$ parasites/ $\mu \mathrm{l}[13,14]$.

All LAMP, LnPCR and qPCR runs included positive (DNA equivalent to $10^{4}$ parasites/ $\mu \mathrm{l}$ ) and negative controls (DNA from peripheral blood from a healthy volunteer). LAMP, LnPCR and qPCR reactions were run in duplicate.

\section{Incubators/fluorimeters and interpretation of LAMP results}

Loopamp $^{\mathrm{TM}}$ Leishmania Detection Kit reactions were carried out in three different devices that allowed for the isothermal incubation required for the LAMP reaction. LAMP reactions were set up in all devices to run for 40 min at $65{ }^{\circ} \mathrm{C}$. A final step of $80{ }^{\circ} \mathrm{C}$ for $5 \mathrm{~min}$ was applied to inactivate the Bst DNA polymerase.

\section{LF-160 incubator}

LF-160 incubator (Eiken Chemical Co.), now commercialized as HumaLoop M incubator (HUMAN, Wiesbaden, Germany), is a benchtop device for isothermal amplification. Results were visualized under blue LED light illumination, using the Fluorescence Visual Check Unit integral to the incubator [15]. Positive samples emit a green fluorescent light. Negative samples do not emit any light.

\section{Genie III ${ }^{\circledR}$ real-time fluorimeter}

The Genie III $^{\oplus}$ (OptiGene Ltd.) is a hand-held, battery operated, device for isothermal amplification and realtime fluorescence detection at the point-of-care. Further information can be found elsewhere [16]. The Genie III ${ }^{\bullet}$ heat block was customized to match the dimension of the Loopamp ${ }^{\text {TM }}$ Leishmania detection tubes and prevent tubes from opening during incubation. To allow for the measurement of the LAMP fluorescence, the Genie III $^{\circ}$ was set up for $470 \mathrm{~nm}$ excitation and $510-560 \mathrm{~nm}$ on the detector side. Prior to using the device for sample measurements, the gain of the detector was adjusted using positive and negative control wells from the Loop$\operatorname{amp}^{\text {Ts }}$ kit.

\section{ESEQuant TS2.2 real-time fluorimeter}

The ESEQuant TS2.2 (Qiagen Lake Constance $\mathrm{GmbH}$ ) is a benchtop device for isothermal amplification and real-time fluorescence detection. Further information can be found elsewhere [17]. Fluorescence was monitored setting the dual fluorescence channel to $470 \mathrm{~nm}$ and $520 \mathrm{~nm}$ for excitation and emission, respectively. Prior to using the device for sample measurements, the gain of the detector was adjusted using positive and negative control wells from the Loopamp ${ }^{\mathrm{TM}}$ kit.

When using the fluorimeters, positive or negative results, as well as amplification time to positivity $(T p)$ in the Genie III $^{\oplus}$, were recorded upon examination of the amplification curves.

\section{Serological and parasitological tests in samples from VL suspects and healthy controls}

Before their inclusion in the WHOCCL-ISCIII collection, samples were characterized, when applicable, by serological and parasitological methods as follows. All the samples from non-confirmed VL suspects and healthy negative controls had a negative result by both the serological and parasitological methods described below.

\section{Immunofluorescent antibody test (IFAT)}

Plasma samples $(1 \mu \mathrm{l})$ from VL suspects and healthy controls were tested by an in-house IFAT following a standard method [18]. In this method the antigen is prepared from L. infantum promastigotes (strain MHOM/ FR/78/LEM-75) and antibody binding is detected using fluorescein isothiocyanate-conjugated sheep anti-human immunoglobulin G (heavy and light chains). The threshold titre for positivity is $\geq 1 / 80$.

\section{Parasitology in bone marrow aspirates from VL suspects}

Bone marrow aspirates were also used to prepare Giemsa smears and/or inoculate NNN cultures. Slides were examined at $1000 \times$ magnification for at least $1 \mathrm{~h}$. 
NNN cultures were maintained at $27{ }^{\circ} \mathrm{C}$, sub-cultured and examined by light microscopy on a weekly basis for at least 4 weeks before a negative result was returned.

\section{Panel of experiments}

The following experiments were conducted to evaluate the performance of Loopamp ${ }^{\mathrm{TM}}$ Leishmania Detection Kit using different methods to run the LAMP reaction and read the results.

\section{Experiment 1}

Ten-fold serial dilutions ranging from $10^{3}$ to $10^{-7}$ parasite equivalents $/ \mu \mathrm{l}$ were prepared with DNA obtained from $L$. infantum promastigotes with the QIAamp DNA Mini Kit. We assumed $200 \mathrm{fg}$ DNA as the equivalent to one parasite [13]. Three $\mu \mathrm{l}$ of each dilution were used in the LAMP, LnPCR and GPCR reactions in this and the other two experiments described below.

\section{Experiment 2}

Leishmania infantum promastigotes from stationary phase culture were counted in a Neubauer chamber, their number adjusted and mixed with heparin-treated peripheral blood from healthy negative control to prepare serial 10-fold dilutions of $200 \mu \mathrm{l}$ each, ranging from $10^{3}$ to $10^{-2}$ parasites/ $\mu$ l. Ninety-five microliters was used in each DNA extraction method described above (QIAamp DNA Mini Kit and Boil \& Spin).

\section{Experiment 3}

DNA was obtained by Boil \& Spin and the QIAamp DNA Mini Kit from $95 \mu \mathrm{l}$ aliquots of five heparintreated human peripheral blood samples and five bone marrow aspirate samples from patients with suspected VL, which had been received at the WHOCCL-ISCIII between September and October 2015 and stored in their collection at $-20{ }^{\circ} \mathrm{C}$. These VL suspects were classified as confirmed or non-confirmed cases based on previous LnPCR, IFAT and parasitology results.

\section{Correlation analysis}

In Experiment 1 we recorded data on time to positivity $(T p)$ for LAMP, obtained with the Genie $\mathrm{III}^{\circ}$ fluorimeter, and qPCR cycle threshold $(C t)$ and parasite load. We estimated the Spearman's correlation coefficient between $T p$ and both $C t$ and parasite load. These analyses were performed with SPSS software (IBM SPSS Statistic 22) and GraphPad Prism v.7.0 (GraphPad Software, San Diego, USA).

\section{Results}

The identification of positive results by examination of the amplification curves obtained with the Genie III ${ }^{\circ}$ and ESEQuant TS2.2 fluorimeters was quite straightforward. Likewise, visualization under blue LED light illumination with the LF-160 incubator allowed easy detection of positive (green) and negative (colourless) samples (Fig. 1).
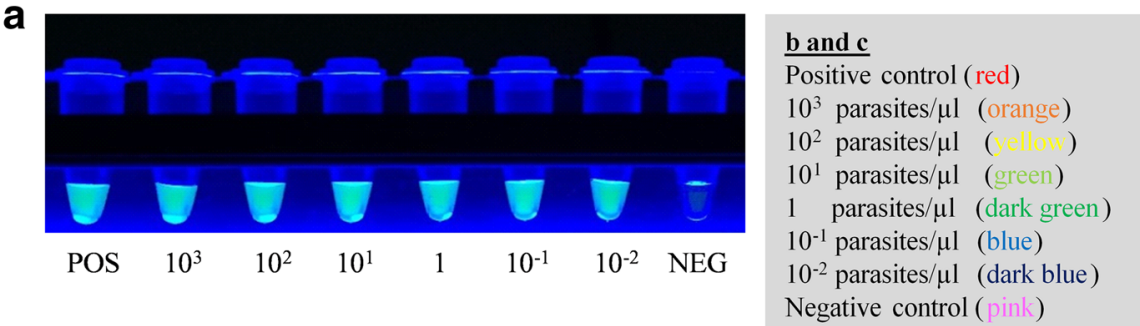

b

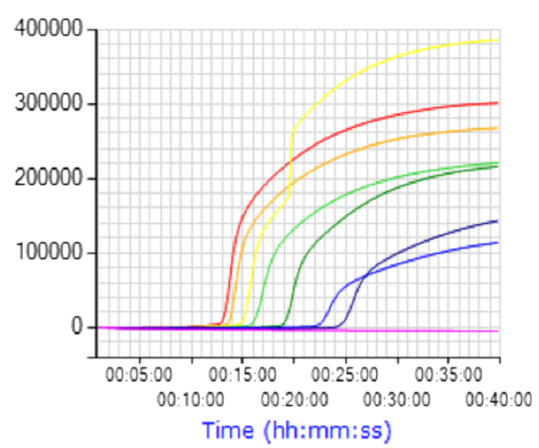

C

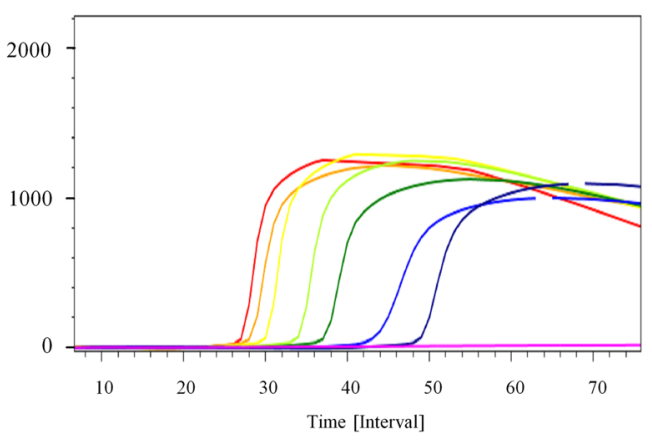

Fig. 1 LAMP reaction results in Experiment 2 with the three different approaches proposed in this study. a Visual inspection under blue LED light illumination (Incubator LF-160) (POS, positive control; NEG, negative control; $10^{3}$ to $10^{-2}$ parasites/ $\mu$ l equivalents). b Amplification curves obtained using the real-time fluorimeter Genie III. Fluorescence in millivolts ( $\mathrm{mV}$ ) on the $y$-axis vs time (min) on the x-axis. c Amplification curves obtained using the real-time fluorimeter ESE-Quant TS2.2. Fluorescence in millivolts ( $\mathrm{mV}$ ) on the $y$-axis ( $\times 100)$ vs time (min) on the $x$-axis 
Independently of the device used for isothermal amplification and detection, LAMP detected all L. infantum DNA samples in the range prepared $\left(10^{3}-10^{-3}\right.$ parasite equivalents $/ \mu \mathrm{l}$ ) in Experiment 1, while the limit of detection for LnPCR and qPCR was $10^{-2}$ parasite equivalents/ $\mu \mathrm{l}$ (Table 1$)$. We also observed a very strong correlation between the Tp obtained with the Genie III ${ }^{\circ}$ fluorimeter and the $C t$ values from qPCR in the same set of samples (Spearman's $r=0.9895, P<0.0001,95 \%$ CI: $0.9601-0.9972)$. Indeed, we also found a very strong correlation between the Tp obtained with the Genie III ${ }^{\circ}$ fluorimeter and the parasite load determined by qPCR (Spearman's $r=-0.9912, P<0.0001,95 \%$ CI: $-0.9977-$ -0.9666) (Fig. 2).

In Experiment 2 (serial 10-fold dilutions of L. infantum promastigotes in heparin-treated peripheral blood), all molecular tests and approaches used detected $L$. infantum spiked samples in the range of $10^{3}$ to $10^{-2}$ parasites/ $\mu$ l, independently of the method used for DNA extraction (QIAamp DNA Mini Kit or Boil \& Spin).

Experiment 3 showed a complete agreement between LnPCR, qPCR and LAMP when it was run in the realtime fluorimeters, independently of the DNA extraction procedure used, as well as in the LF-160 incubator when DNA samples were prepared with the QIAamp DNA Mini Kit. However, when samples prepared with the Boil \& Spin method were run in the LF-160 incubator, the examination under blue LED light returned three discordant results even after repeated testing (Table 2). It was not possible to get a clear result for a bone marrow aspirate from a VL confirmed patient (VL6), and two samples from non-confirmed VL suspects (VL7-peripheral blood and VL8-bone marrow) returned a signal that was judged as positive when all other tests were negative (LnPCR, qPCR and LAMP as well as serology and parasitology).

\section{Discussion}

Leishmaniasis is a neglected tropical disease that has its largest impact on the poorest of the poor in endemic regions, which quite often do not have access to an accurate diagnosis due to a limited health service infrastructure. Prompt diagnosis and treatment is key to reduce the morbidity and stigma associated with cutaneous leishmaniasis (CL) and to avoid the chronic wasting and death of those affected by visceral leishmaniasis (VL) [19]. NAATs (principally PCR-based methods) have proven to be advantageous in the diagnosis of leishmaniasis, allowing the accurate diagnosis of $\mathrm{CL}$ even in lesions of long duration. The latter has enabled confirmatory diagnosis of VL using peripheral blood, in opposition to more invasive procedures such as bone marrow or splenic aspiration required for microscopy [20-23]. The diagnosis and management of leishmaniasis would benefit from the implementation of accurate NAATs at the POC.

LAMP is a simple and robust NAAT, and different studies have shown a number of applications of prototype LAMP tests in the field of leishmaniasis. Several prototypes have shown to be useful in detecting Leishmania infection in sand flies, diagnosis of canine leishmaniasis, human VL, CL and post-kala-azar dermal leishmaniasis. In general, these studies have reported high sensitivity and specificity assessing LAMP results either using direct examination with the naked eye [2432], or fluorimetry or turbidimetry [33-35]. Regarding fluorimetry, both Genie $\mathrm{III}^{\circ}$ and ESEQuant TS2.2 devices have been used in the diagnosis of different pathogens using LAMP [36-41], to the best of our knowledge this is the first time these approaches are used to detect Leishmania DNA using the Loopamp ${ }^{\mathrm{Tm}}$ Leishmania Detection Kit.

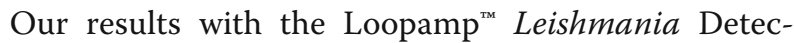
tion Kit and different detection systems show a strong correlation with LnPCR and qPCR methods normally employed by the WHOCCL-ISCIII for the diagnosis of different forms of leishmaniasis as well as in epidemiological investigations [12-14, 42-49]. When using DNA purified with the QIAamp DNA Mini Kit LAMP returned a one-log higher analytical sensitivity (equivalent to $10^{-3}$ parasites/ $\mu \mathrm{l}$ ) than LnPCR or qPCR $\left(10^{-2}\right.$ parasites $\left./ \mu \mathrm{l}\right)$, which might well be a reflection of

Table 1 Results obtained by using DNA isolated with QIAgen columns with the different instruments in Experiment 1

\begin{tabular}{|c|c|c|c|c|c|c|c|c|c|c|c|}
\hline \multirow[t]{2}{*}{ Instrument } & \multicolumn{11}{|c|}{ L. infantum 10-fold DNA dilutions of parasite equivalents/ $\mu$ l } \\
\hline & $10^{3}$ & $10^{2}$ & 10 & 1 & $10^{-1}$ & $10^{-2}$ & $10^{-3}$ & $10^{-4}$ & $10^{-5}$ & $10^{-6}$ & $10^{-7}$ \\
\hline LF-160 & Pos & Pos & Pos & Pos & Pos & Pos & Pos & Neg & Neg & Neg & Neg \\
\hline Genie $\|^{\circledR}$ & Pos & Pos & Pos & Pos & Pos & Pos & Pos & Neg & Neg & Neg & Neg \\
\hline Tp (min:sec) & $13: 30$ & $14: 30$ & $16: 15$ & $17: 45$ & $21: 45$ & $24: 00$ & $34: 15$ & 0 & 0 & 0 & 0 \\
\hline ESEQuant TS2.2 & Pos & Pos & Pos & Pos & Pos & Pos & Pos & Neg & Neg & Neg & Neg \\
\hline $\operatorname{LnPCR}$ & Pos & Pos & Pos & Pos & Pos & Pos & Neg & Neg & Neg & Neg & Neg \\
\hline qPCR & Pos & Pos & Pos & Pos & Pos & Pos & Neg & Neg & Neg & Neg & $\mathrm{Neg}$ \\
\hline $\mathrm{Ct}$ & 19.1 & 22.5 & 25.6 & 28.4 & 30.7 & 32.1 & Neg & Neg & Neg & Neg & Neg \\
\hline
\end{tabular}

Abbreviations: Pos positive, Neg negative 

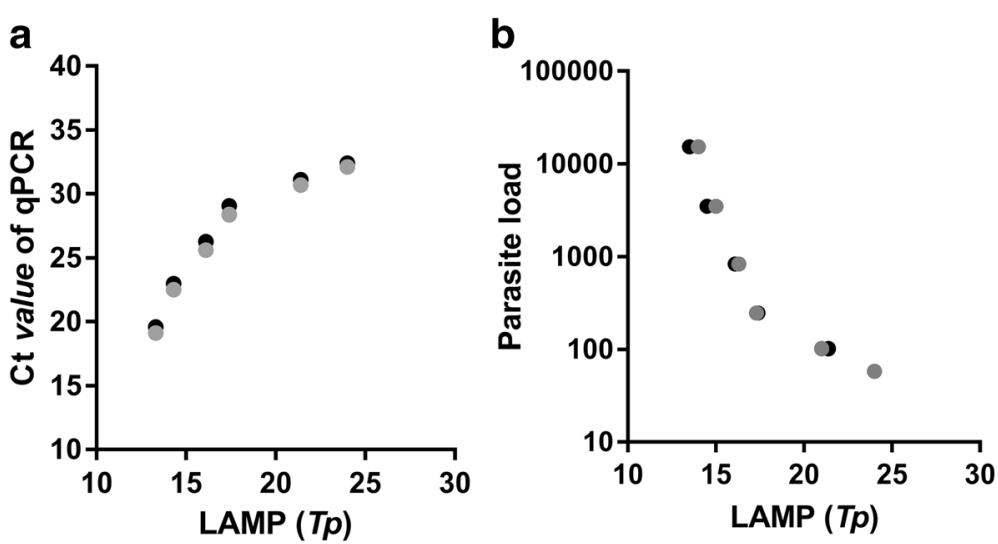

Fig. 2 Correlation between LAMP and $\mathrm{qPCR}$ in the same set of samples $\left(10^{3}\right.$ to $10^{-2}$ parasites/ $\mu$ ), from Experiment 1 . a Correlation between the Tp obtained with the Genie II ${ }^{\otimes}$ fluorimeter and the Ct values from qPCR (Spearman's $r=0.9895, P=0.0001$ ). b Correlation between the Tp obtained with the Genie II ${ }^{\circledR}$ fluorimeter and parasite load from qPCR (Spearman's $r=-0.9912, P=0.0001$ )

the number of copies per Leishmania genome of the DNA targets in these NAATs (Experiment 1). It is worth noting that while LnPCR and qPCR target the $18 S$ rRNA gene (> 100 copies/genome), the Loopamp ${ }^{\mathrm{Tm}}$ Leishmania Detection Kit targets both $18 S$ rRNA and kDNA minicirles (the later with > 1000 copies/genome) [50]. This high sensitivity has been demonstrated in the set of clinical samples from suspected VL cases included in this study.

When we used fresh blood spiked with L. infantum promastigotes (Experiment 2), the LAMP test showed a strong correlation with LnPCR and qPCR, independently of the method used for DNA preparation. It was only in clinical samples prepared with the Boil \& Spin method (Experiment 3) that we found three discrepancies when the reactions were run in the LF-160 incubator and the results examined by the naked eye under blue LED light. This problem with naked eye examination of LAMP results from crude DNA lysates from blood has been reported elsewhere $[9,10]$. As we did not see this problem in Experiment 2, we suggest this might be related to the use of fresh versus frozen stored samples, as the clinical samples used in Experiment 3 were collected in 2015 and kept at $-20{ }^{\circ} \mathrm{C}$ since then. We can speculate that excess hemolysis in frozen samples affected the interpretation of LAMP results by the naked eye when DNA is prepared with the Boil \& Spin method $[51,52]$.

The possibility of using a ready-to-use amplification kit with a simple sample preparation method (Boil \& Spin) and a fluorimeter could be attractive for the diagnosis of visceral leishmaniasis in resource-limited health infrastructures. The accuracy of this approach for other clinical manifestations of leishmaniasis such as cutaneous leishmaniasis or post-kalaazar leishmaniasis should also be tested. In addition, the accurate detection of asymptomatic dogs acting as reservoir

Table 2 Results obtained with the different instruments in each of the different experiments proposed. Discordant results are shown in bold letters. Sample order in the table is the same as in LAMP analyses

\begin{tabular}{|c|c|c|c|c|c|c|c|c|c|}
\hline \multirow[t]{2}{*}{ Sample ID/ patient type } & \multirow[t]{2}{*}{ Sample type } & \multirow[t]{2}{*}{$\operatorname{LnPCR}$} & \multirow[t]{2}{*}{ qPCR } & \multicolumn{6}{|c|}{ LAMP results by instrument/DNA preparation } \\
\hline & & & & $\begin{array}{l}\text { LF-160 } \\
\text { /B\&S }\end{array}$ & $\begin{array}{l}\text { LF-160 } \\
\text { /QIA }\end{array}$ & $\begin{array}{l}\text { Genie } \|^{\oplus} \\
\text { /B\&S }\end{array}$ & $\begin{array}{l}\text { Genie } \|^{\circledR} \\
\text { /QIA }\end{array}$ & $\begin{array}{l}\text { ESEQuant } \\
\text { TS2.2/B\&S }\end{array}$ & $\begin{array}{l}\text { ESEQuant } \\
\text { TS2.2/QIA }\end{array}$ \\
\hline $\mathrm{VL} 1 / \mathrm{C}$ & Peripheral blood & Pos & Pos & Pos & Pos & Pos & Pos & Pos & Pos \\
\hline $\mathrm{VL} 2 / \mathrm{C}$ & Bone marrow aspirate & Pos & Pos & Pos & Pos & Pos & Pos & Pos & Pos \\
\hline $\mathrm{VL} 3 / \mathrm{C}$ & Peripheral blood & Pos & Pos & Pos & Pos & Pos & Pos & Pos & Pos \\
\hline$V L 4 / C$ & Peripheral blood & Pos & Pos & Pos & Pos & Pos & Pos & Pos & Pos \\
\hline VL5/NC & Bone marrow aspirate & Neg & Neg & Neg & Neg & Neg & Neg & Neg & Neg \\
\hline VL6/C & Bone marrow aspirate & Pos & Pos & Unc & Pos & Pos & Pos & Pos & Pos \\
\hline $\mathrm{VL} 7 / \mathrm{NC}$ & Peripheral blood & Neg & Neg & Pos & Neg & Neg & Neg & Neg & Neg \\
\hline VL8/NC & Bone marrow aspirate & Neg & Neg & Pos & Neg & Neg & Neg & Neg & Neg \\
\hline VL9/C & Bone marrow aspirate & Pos & Pos & Pos & Pos & Pos & Pos & Pos & Pos \\
\hline VL10/NC & Peripheral blood & Neg & Neg & Neg & Neg & Neg & Neg & Neg & Neg \\
\hline
\end{tabular}

Abbreviations: ID Identification number in this study, Pos Positive result, Neg negative result, C confirmed VL case, NC non-confirmed VL case, Unc uncertain result 
for zoonotic visceral leishmaniasis and the confirmation of canine visceral leishmaniasis cases in the field would be valuable for the control of leishmaniasis.

In summary, our study shows a good performance of the Loopamp ${ }^{\text {TM }}$ Leishmania Detection Kit using different devices for amplification and interpretation of results, as well as different approaches for DNA preparation. The use of real-time fluorimeters presents the additional advantage of an objective assessment of the amplification, which is less affected by the background components present in crude DNA lysates obtained with the Boil \& Spin method. Additional advantages of these fluorimeters is their portability and that they offer opportunities for diagnostic connectivity using Wi-Fi or Bluetooth ${ }^{\circ}$ $[16,17]$. The high correlation between LAMP $T p$ and both qPCR $C t$ values and parasite load also opens the possibility of exploring the use of real-time LAMP as a semi-quantitative test, as proposed by other authors [53-59]. Similarly, though not validated in this study, the use of real-time turbidimeters would also provide significant advantages in the interpretation of LAMP results $[58,59]$.

\section{Conclusions}

The Loopamp ${ }^{\text {Tw }}$ Leishmania Detection Kit has shown a very good diagnostic performance in this small-scale study, and the possibility of using a simple sample preparation method (Boil \& Spin) and a portable and robust real-time fluorimeter opens an avenue for the diagnosis of leishmaniasis at the POC, enabling treatment when confirmatory diagnosis is required. This test can support the diagnosis of VL in situations in which serological diagnosis is useless such as in VL relapses and test-of-cure, VL/HIV co-infection, and the diagnosis of $\mathrm{CL}$ cases that require confirmatory diagnosis to initiate systemic treatment, which often presents high toxicity. This promising approach could also be explored in veterinary public health for the diagnosis of canine leishmaniasis.

\footnotetext{
Abbreviations

CL: cutaneous leishmaniasis; Ct: cycle threshold; FIND: Foundation for Innovative New Diagnostics; IFAT: immunofluorescence antibody test; kDNA: kinetoplast deoxyribonucleic acid; LAMP: loop-mediated isothermal amplification; LED: light-emitting diode; LnPCR: Leishmania nested-PCR; NAATs: nucleic acid amplification tests; PCR: polymerase chain reaction; POC: point-of-care; qPCR: real-time quantitative PCR; rRNA: ribosomal ribonucleic acid; Tp: amplification time to positivity; VL: visceral leishmaniasis; WHOCCL-ISCIII: WHO Collaborating Centre for Leishmaniasis, Instituto de Salud Carlos III, Spain

Funding

This work was supported by funds from the Federal Ministry of Education and Research, Germany (KfW grant reference number 202060457, Development of Products for the Prevention, Diagnosis and Treatment of Neglected and Poverty Related Diseases; https://www.bmbf.de/en/ index.html) and the Ministry of Foreign Affairs, Government of the Netherlands (Activity Ref. Nr. 22211, Developing Innovative Diagnostics to Address Poverty-Related
}

Diseases; https://www.rijksoverheid.nl/ministeries/ministerie-van-buitenlandse-zaken\#ref-minbuza.nl). E Carrillo was supported by a contract from RD16CIII/0003/0002 Red de Investigación Cooperativa de Enfermedades Tropicales, Subprograma RETICS del Plan Estatal de I+D+I 2013-2016, co-funded by FEDER "Una manera de hacer Europa" funds. The funders had no role in study design, data collection and analysis, decision to publish, or preparation of the manuscript.

\section{Availability of data and materials}

The datasets used and/or analysed during the current study are available from the corresponding author upon reasonable request.

\section{Authors' contributions}

Conceptualization: EC, JM, SB and IC. Methodology: AVIM, EC, TB, SB and IC. Validation: AVIM, EC and IC. Formal analysis: AVIM, EC and IC. Investigation in site: AVIM, EC, CC and CS. Data curation: AVIM, EC and IC. Writing and original draft preparation: AVIM, EC and IC. Writing, review and editing: AVIM, EC, JM, TB, SB and IC. Supervision: EC, JM and IC. Project administration: EC, $J M$ and IC. Funding acquisition: JM and SB. All authors read and approved the final manuscript.

\section{Ethics approval and consent to participate}

Recruitment and sample collection from VL suspects was performed in accordance with guidelines for good clinical practice. The study was approved by the Hospital de Fuenlabrada Ethics and Research Committee (APR 12-67). All study subjects provided their informed written consent to be included.

\section{Competing interests}

The authors declare that they have no competing interests.

\section{Publisher's Note}

Springer Nature remains neutral with regard to jurisdictional claims in published maps and institutional affiliations.

\section{Author details}

${ }^{1}$ WHO Collaborating Centre for Leishmaniasis, National Centre for Microbiology, Instituto de Salud Carlos III, Madrid, Spain. ${ }^{2}$ Foundation for Innovative New Diagnostics, Geneva, Switzerland.

Received: 30 January 2018 Accepted: 6 April 2018

Published online: 17 April 2018

\section{References}

1. Notomi T, Okayama H, Masubuchi H, Yonekawa T, Watanabe K, Amino N, et al. Loop-mediated isothermal amplification of DNA. Nucleic Acids Res. 2000;28:e63.

2. Notomi T, Mori Y, Tomita N, Kanda H. Loop-mediated isothermal amplification (LAMP): principle, features, and future prospects. J Microbiol. 2015;53:1-5.

3. World Health Organization. The use of loop-mediated isothermal amplification (TB-LAMP) for the diagnosis of pulmonary tuberculosis: policy guidance. WHO/HTM/TB/2016.07. http://apps.who.int/iris/bitstream/handle/ 10665/249154/9789241511186-eng.pdf?sequence=1. Accessed 15 Feb 2017.

4. Tegegne B, Getie S, Lemma W, Mohon AN, Pillai DR. Performance of loopmediated isothermal amplification (LAMP) for the diagnosis of malaria among malaria suspected pregnant women in Northwest Ethiopia. Malar J. 2017;16:34.

5. Perera RS, Ding XC, Tully F, Oliver J, Bright N, Bell D, et al. Development and clinical performance of high throughput loop-mediated isothermal amplification for detection of malaria. PLoS One. 2017;12(2):e0171126.

6. Peeling RW, McNerney R. Emerging technologies in point-of-care molecular diagnostics for resource-limited settings. Expert Rev Mol Diagn. 2014;14: 525-34.

7. Kaneko H, Kawana T, Fukushima E, Suzutani T. Tolerance of loop-mediated isothermal amplification to a culture medium and biological substances. J Biochem Biophys Methods. 2007;70:499-501.

8. Safavieh M, Kanakasabapathy MK, Tarlan F, Ahmed MU, Zourob M, Asghar $W$, et al. Emerging loop-mediated isothermal amplification-based microchip and microdevice technologies for nucleic acid detection. ACS Biomater Sci Eng. 2016;2:278-94. 
9. Paris DH, Imwong M, Faiz AM, Hasan M, Yunus EB, Silamut K, et al. Loopmediated isothermal PCR (LAMP) for the diagnosis of falciparum malaria. Am J Trop Med Hyg. 2007;77(5):972-6.

10. Besuschio SA, Llano Murcia M, Benatar AF, Monnerat S, Cruz I, Picado A et al. Analytical sensitivity and specificity of a loop-mediated isothermal amplification (LAMP) kit prototype for detection of Trypanosoma cruzi DNA in human blood samples. PLoS Negl Trop Dis. 2017;11:e0005779.

11. Fischbach J, Xander NC, Frohme M, Glökler JF. Shining a light on LAMP assays - a comparison of LAMP visualization methods including the novel use of berberine. Biotechniques. 2015;58:189-94.

12. Cruz I, Chicharro C, Nieto J, Bailo B, Cañavate C, Figueras MC, et al. Comparison of new diagnostic tools for management of pediatric Mediterranean visceral leishmaniasis. J Clin Microbiol. 2006;44(7):2343.

13. Cruz I, Millet A, Carrillo E, Chenik M, Salotra P, Verma S, et al. An approach for interlaboratory comparison of conventional and real-time PCR assays for diagnosis of human leishmaniasis. Exp Parasitol. 2013;134:281-9.

14. Miró G, Oliva G, Cruz I, Cañavate C, Mortarino M, Vischer C, et al. Multicentric, controlled clinical study to evaluate effectiveness and safety of miltefosine and allopurinol for canine leishmaniosis. Vet Dermatol. 2009;20: 397-404.

15. HumanLoop M. Easy-to-use LoopampTM technology for primary and district laboratories. https://www.human.de/products/molecular-dx/isothermalamplification/instruments-primary-districtlabs-level-i-ii/humaloop-mmultiple-parameters/\#c10756. Accessed 20 Nov 2017.

16. Genie III. Molecular detection at point of application. http://www.optigene. co.uk/instruments/instrument-genie-iii/. Accessed 20 Nov 2017.

17. ESEQuant TS2. For measurement of fluorescence in tubes for isothermal nucleic acid amplification and other temperature-controlled applications. https:/www.qiagen.com/ch/products/custom-solutions/automation/eseinstruments/esequant-ts2?akamai-feo=off. Accessed 20 Nov 2017.

18. Bray RS. Immunodiagnosis of leishmaniasis. In: Chang KP, Bray RS, editors. Leishmaniasis. Amsterdam. Netherlands: Elsevier; 1985. p. 177-82.

19. World Health Organization (2010) Control of the leishmaniasis: report of a meeting of the WHO Expert Committee on the Control of Leishmaniases, Geneva 22-26 March 2010. WHO technical report series No. 949. Geneva: WHO. http://apps.who.int/iris/bitstream/handle/10665/44412/WHO_TRS_ 949_eng.pdf?sequence=1. Accessed 8 June 2017.

20. Garcia AL, Parrado R, De Doncker S, Bermudez H, Dujardin JC. American tegumentary leishmaniasis: direct species identification of Leishmania in non-invasive clinical samples. Trans R Soc Trop Med Hyg. 2007;101:368-71.

21. Boggild AK, Ramos AP, Espinosa D, Valencia BM, Veland N, MirandaVerastegui $C$, et al. Clinical and demographic stratification of test performance: a pooled analysis of five laboratory diagnostic methods for American cutaneous leishmaniasis. Am J Trop Med Hyg. 2010;83:345-50.

22. de Vries HJ, Reedijk SH, Schallig HD. Cutaneous leishmaniasis: recent developments in diagnosis and management. Am J Clin Dermatol. 2015;16: 99-109.

23. de Ruiter CM, van der Veer C, Leeflang MM, Deborggraeve S, Lucas C, Adams ER. Molecular tools for diagnosis of visceral leishmaniasis: systematic review and meta-analysis of diagnostic test accuracy. J Clin Microbiol. 2014; 52:3147-55.

24. Takagi H, Itoh M, Islam MZ, Razzaque A, Ekram AR, Hashighuchi Y, et al. Sensitive, specific, and rapid detection of Leishmania donovani DNA by loopmediated isothermal amplification. Am J Trop Med Hyg. 2009;81:578-82.

25. Nzelu CO, Gomez EA, Cáceres AG, Sakurai T, Martini-Robles L, Uezato H, et al. Development of a loop-mediated isothermal amplification method for rapid mass-screening of sand flies for Leishmania infection. Acta Trop. 2014;132:1-6.

26. Tiwananthagorn S, Kato H, Yeewa R, Muengpan A, Polseela R, Leelayoova S. Comparison of LAMP and PCR for molecular mass screening of sand flies for Leishmania martiniquensis infection. Mem Inst Oswaldo Cruz. 2017;112: 100-7.

27. Kothalawala HS, Karunaweera ND. Loop-mediated isothermal amplification assay as a sensitive diagnostic tool for Leishmania donovani infections in Sri Lanka. Ceylon Med J. 2016;61:68-70.

28. Nzelu CO, Cáceres AG, Guerrero-Quincho S, Tineo-Villafuerte E, RodriquezDelfin L, Mimori T, et al. A rapid molecular diagnosis of cutaneous leishmaniasis by colorimetric malachite green-loop-mediated isothermal amplification (LAMP) combined with an FTA card as a direct sampling tool. Acta Trop. 2016;153:116-9.

29. Ghasemian M, Gharavi MJ, Akhlaghi L, Mohebali M, Meamar AR, Aryan E, et al. Development and assessment of loop-mediated isothermal amplification
(LAMP) assay for the diagnosis of human visceral leishmaniasis in Iran. Iran J Parasitol. 2014:9:50-9.

30. Verma S, Avishek K, Sharma V, Negi NS, Ramesh V, Salotra P. Application of loop-mediated isothermal amplification assay for the sensitive and rapid diagnosis of visceral leishmaniasis and post-kala-azar dermal leishmaniasis. Diagn Microbiol Infect Dis. 2013;75:390-5.

31. Verma S, Singh R, Sharma V, Bumb RA, Negi NS, Ramesh V, et al. Development of a rapid loop-mediated isothermal amplification assay for diagnosis and assessment of cure of Leishmania infection. BMC Infect Dis. 2017; 17:223.

32. Khan MG, Bhaskar KR, Salam MA, Akther T, Pluschke G, Mondal D. Diagnostic accuracy of loop-mediated isothermal amplification (LAMP) for detection of Leishmania DNA in buffy coat from visceral leishmaniasis patients. Parasit Vectors. 2012;5:280

33. Chaouch M, Mhadhbi M, Adams ER, Schoone GJ, Limam S, Gharbi Z, et al. Development and evaluation of a loop-mediated isothermal amplification assay for rapid detection of Leishmania infantum in canine leishmaniasis based on cysteine protease B genes. Vet Parasitol. 2013;198:78-84.

34. Gao CH, Ding D, Wang JY, Steverding D, Wang X, Yang YT, et al. Development of a LAMP assay for detection of Leishmania infantum infection in dogs using conjunctival swab samples. Parasit Vectors. 2015:8:370.

35. Abbasi I, Kirstein OD, Hailu A, Warburg A. Optimization of loop-mediated isothermal amplification (LAMP) assays for the detection of Leishmania DNA in human blood samples. Acta Trop. 2016;162:20-6.

36. Mahony J, Chong S, Bulir D, Ruyter A, Mwawasi K, Waltho D. Multiplex loopmediated isothermal amplification (M-LAMP) assay for the detection of influenza $\mathrm{A} / \mathrm{H1}, \mathrm{A} / \mathrm{H} 3$ and influenza $\mathrm{B}$ can provide a specimen-to-result diagnosis in 40 min with single genome copy sensitivity. J Clin Virol. 2013; 58:127-31.

37. Neeraja M, Lakshmi V, Lavanya V, Priyanka EN, Parida MM, Dash PK, et al. Rapid detection and differentiation of dengue virus serotypes by NS1 specific reverse transcription loop-mediated isothermal amplification (RTLAMP) assay in patients presenting to a tertiary care hospital in Hyderabad, India. J Virol Methods. 2015;211:22-31.

38. Jelocnik M, Islam MM, Madden D, Jenkins C, Branley J, Carver S, et al. Development and evaluation of rapid novel isothermal amplification assays for important veterinary pathogens: Chlamydia psittaci and Chlamydia pecorum. PeerJ. 2017:5:e3799.

39. Curtis KA, Niedzwiedz PL, Youngpairoj AS, Rudolph DL, Owen SM. Real-time detection of HIV-2 by reverse transcription-loop-mediated isothermal amplification. J Clin Microbiol. 2014;52(7):2674-6.

40. Ye L, Li Y, Zhao J, Zhang Z, Meng H, Yan H, et al. Development of a real-time loop-mediated isothermal amplification assay for the sensitive and rapid detection of Listeria monocytogenes. Lett Appl Microbiol. 2015:61:85-90.

41. Kurosaki Y, Magassouba N, Oloniniyi OK, Cherif MS, Sakabe S, Takada A, et al. Development and evaluation of reverse transcription-loop-mediated isothermal amplification (RT-LAMP) assay coupled with a portable device for rapid diagnosis of Ebola virus disease in Guinea. PLoS Negl Trop Dis. 2016; 10:e0004472.

42. Cruz I, Cañavate C, Rubio JM, Morales MA, Chicharro C, Laguna F, et al. A nested polymerase chain reaction $(L n-P C R)$ for diagnosing and monitoring Leishmania infantum infection in patients co-infected with human immunodeficiency virus. Trans R Soc Trop Med Hyg. 2002;96(Suppl. 1):S185-9.

43. Alvar J, Bashaye S, Argaw D, Cruz I, Aparicio P, Kassa A, et al. Kala-azar outbreak in Libo Kemkem, Ethiopia: epidemiologic and parasitologic assessment. Am J Trop Med Hyg. 2007;77:275-82.

44. Cruz I, Acosta L, Gutiérrez MN, Nieto J, Cañavate C, Deschutter J, et al. A canine leishmaniasis pilot survey in an emerging focus of visceral leishmaniasis: Posadas (Misiones, Argentina). BMC Infect Dis. 2010;10:342.

45. Cañavate C, Herrero M, Nieto J, Cruz I, Chicharro C, Aparicio P, et al. Evaluation of two rK39 dipstick tests, direct agglutination test, and indirect fluorescent antibody test for diagnosis of visceral leishmaniasis in a new epidemic site in highland Ethiopia. Am J Trop Med Hyg. 2011;84:102-6.

46. Ferreira Ede C, Cruz I, Cañavate C, de Melo LA, Pereira AA, Madeira FA, et al. Mixed infection of Leishmania infantum and Leishmania braziliensis in rodents from endemic urban area of the New World. BMC Vet Res. 2015;11:71.

47. Oliva G, Nieto J, Foglia Manzillo V, Cappiello S, Fiorentino E, Di Muccio T, et al. A randomised, double-blind, controlled efficacy trial of the LiESP/QA- 
21 vaccine in naïve dogs exposed to two Leishmania infantum transmission seasons. PLoS Negl Trop Dis. 2014;8:e3213.

48. Ibarra-Meneses AV, Carrillo E, Sánchez C, García-Martínez J, López Lacomba D, San Martin JV, et al. Interleukin-2 as a marker for detecting asymptomatic individuals in areas where Leishmania infantum is endemic. Clin Microbiol Infect. 2016;22:739.e1-4.

49. Ibarra-Meneses AV, Ghosh P, Hossain F, Chowdhury R, Mondal D, Alvar J, et al. IFN- $\gamma$, IL-2, IP-10, and MIG as biomarkers of exposure to Leishmania spp., and of cure in human visceral leishmaniasis. Front Cell Infect Microbiol. 2017;7:200.

50. Antinori S, Calattini S, Longhi E, Bestetti G, Piolini R, Magni C, et al. Clinical use of polymerase chain reaction performed on peripheral blood and bone marrow samples for the diagnosis and monitoring of visceral leishmaniasis in HIV-infected and HIV-uninfected patients: a single-center, 8-year experience in Italy and review of the literature. Clin Infect Dis. 2007:44:1602-10.

51. Nederhand RJ, Droog S, Kluft C, Simoons ML, de Maat MP. Investigators of the EUROPA trial. Logistics and quality control for DNA sampling in large multicenter studies. J Thromb Haemost. 2003;1:987-91.

52. Shabihkhani M, Lucey GM, Wei B, Mareninov S, Lou JJ, Vinters HV, et al. The procurement, storage, and quality assurance of frozen blood and tissue biospecimens in pathology, biorepository, and biobank settings. Clin Biochem. 2014:47:258-66.

53. Mori Y, Kitao M, Tomita N, Notomi T. Real-time turbidimetry of LAMP reaction for quantifying template DNA. J Biochem Biophys Methods. 2004; 59:145-57.

54. Drame PM, Fink DL, Kamgno J, Herrick JA, Nutman TB. Loop-mediated isothermal amplification for rapid and semiquantitative detection of Loa loa infection. J Clin Microbiol. 2014;52:2071-7.

55. Odari EO, Maiyo A, Lwembe R, Gurtler L, Eberle J, Nitschko H. Establishment and evaluation of a loop-mediated isothermal amplification (LAMP) assay for the semi-quantitative detection of HIV-1 group M virus. J Virol Methods. 2015;212:30-8

56. Oscorbin IP, Belousova EA, Zakabunin Al, Boyarskikh UA, Filipenko ML. Comparison of fluorescent intercalating dyes for quantitative loop-mediated isothermal amplification (qLAMP). Biotechniques. 2016:61:20-5.

57. Yang Q, Domesle K, Wang F, Ge B. Rapid detection of Salmonella in food and feed by coupling loop-mediated isothermal amplification with bioluminescent assay in real-time. BMC Microbiol. 2016;16:112.

58. Molecular diagnostic. Isothermal Amplification. https://www.human.de/ products/molecular-dx/. Accessed 20 Nov 2017.

59. Loopamp real time turbidimeter (LA-500). http://loopamp.eiken.co.jp/e/ products/la500/. Accessed 20 Nov 2017

\section{Ready to submit your research? Choose BMC and benefit from:}

- fast, convenient online submission

- thorough peer review by experienced researchers in your field

- rapid publication on acceptance

- support for research data, including large and complex data types

- gold Open Access which fosters wider collaboration and increased citations

- maximum visibility for your research: over $100 \mathrm{M}$ website views per year

At BMC, research is always in progress.

Learn more biomedcentral.com/submissions 